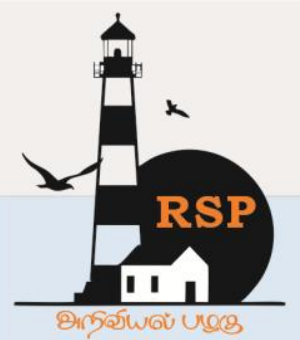

INTERNATIONAL RESEARCH JOURNAL ON ADVANCED SCIENCE HUB

Special Issue of First International Conference on Science, Technology \& Management (ICSTM-2020)

\title{
A Comprehensive Review on the Materials for Chemical Engineering
}

\section{Vivek Kumar ${ }^{1}$, E. Bhawani ${ }^{2}$, T. Babu ${ }^{3}$, Balgovind Tiwari ${ }^{4}$, R.N.P. Choudhary ${ }^{5}$}

${ }^{1}$ Assistant Professor, Dept. of Chemical Engineering, IIIT-RKValley, RGUKT, A.P., India

${ }^{2,4}$ Assistant Professor, Dept. of Physics, IIIT-RKValley, RGUKT, A.P., India

${ }^{3}$ Teacher, Dept. of Physics, Sri Chaitanya High School, Vempalli, Kadapa, A.P., India

${ }^{5}$ Professor, Dept. of Physics, ITER-SOA University, Bhubaneswar, Orissa, India.

balgovindtiwari@gmail.com ${ }^{4}$

\begin{abstract}
The physics and chemistry of materials is being well studied by physicists and chemists respectively. Specifically in chemical engineering, materials science is one of the progressive field where the chemical engineers are involved in the invention and alteration of properties of different materials and/or substances. For instance, the plastic science has been and is being evolved by the research and development of large number of scientists and researchers across the world. This review provide the fundamental knowledge on the different types of materials for the chemical engineering research. A comprehensive review on the history, development, processing and properties of ceramics is demonstrated in this work.
\end{abstract}

Keywords:Materials; Chemical Engineering; Polymers; Ceramics;

\section{Introduction}

In line with the material scientists and the corresponding technologists, chemical engineers hold central importance in the cutting edge development of materials and the related technologies. Due to the existence of materials that are chemically active and reactive, it is worth to study the chemical properties and/or response of different types of materials. The materials include ceramics [1], polymers, metals, nanomaterials, composites, etc. Basically, the materials can be divided into three major categories such as metals, semiconductors, and Nonmetals/insulators/dielectrics. Again the three categories are further combined to form other type, as it is shown in figure 1 .

The metals can be further divided into high temperature metals, light weight metals, etc. Nonmetals are also divided into organic and inorganic materials. Examples of inorganic materials refer to ceramics, glasses, silicates, etc. Examples of organic materials refer mainly to polymers.

\subsection{Ceramics}

Keramos is a Greek word, from which the ceramic term has been derived. The Greek word basically refer to the clay of pottery. The firing of this clay, at relatively high temperatures, is usually known as pottery. After firing, mixing of clay with water yields a paste that can be molded. Goods/articles can be prepared from the yielded paste, on drying and further firing. One can infer that the ceramics involve in the process of heating/firing when they are processed [2].

\subsubsection{Basic Properties of Ceramics}




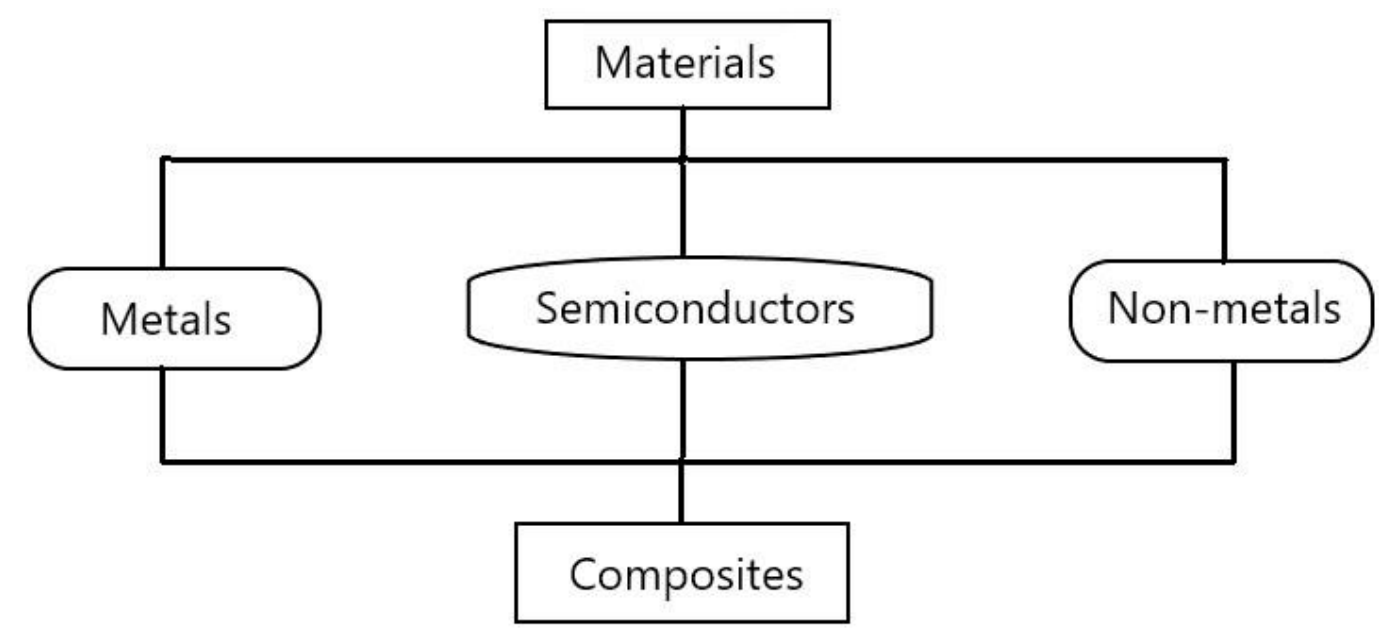

Fig.1. Material Categories

(1) At room temperature, compounds of ceramic type are brittle in nature. This is due to the presence of ionic-covalent bonds between the ceramic constituent atoms.

(2) Basically in metals, the presence of valence electrons results in electrical and thermal conductivity [3]. Similarly in diamond also, there will be thermal conduction that exists due to phonons not due to the free charge carriers. In fact, the diamond is classified as a ceramic. Also, $\mathrm{ReO}_{3}$ exhibit electrical conduction process.

(3) Though the ceramics are brittle, the toughness can be enhanced by synthesizing composites.

(4) The beauty of ceramics is that they are not chemical sensitive. So they are said to be stable in the chemical environment. For instance, Pyrex glass is widely used in the laboratories of chemistry. Because, it is chemically inert.

(5) Optical transparency is one of the property possessed by some ceramics. The wide energy band gap of ceramics corresponds to their good optical transparency.

\subsection{Polymers}

Another class of non-metals include polymers. The word polymer has 'poly' and 'mer' terms that can be referred as 'many' and 'chemical unit' respectively. Polymers are made such that the carbon atoms are in bond with other atoms. Chemical engineers can synthesize numerous polymers with the help of only eight basic elements such as hydrogen $(\mathrm{H})$, carbon (c), nitrogen $(\mathrm{N})$, oxygen $(\mathrm{O})$, fluorine $(\mathrm{F})$, silicon $(\mathrm{Si})$, chlorine $(\mathrm{Cl})$, and Sulphur (S). Using the above mentioned elements, it is possible to prepare very complex and heavier molecules. Because the carbon atoms can combine with other elements in the form of long chains, resulting in large molecules. For example, methane $\left(\mathrm{CH}_{4}\right)$ is lighter than ethane $\left(\mathrm{C}_{2} \mathrm{H}_{6}\right)$. On further addition of $\mathrm{CH}_{2}$ units, molecular weight increases and hence the state changes i.e. pentane $\left(\mathrm{C}_{5} \mathrm{H}_{12}\right)$ is liquid at room temperature. Similarly, addition of $\mathrm{CH}_{2}$ units yields paraffin $\left(\mathrm{C}_{18} \mathrm{H}_{38}\right)$. The general state of paraffin wax is solid. Indeed, the products made of polymers have got huge commercial success. Because the production percentage of polymer products is very much larger than the metal based products [4]. Basic properties of polymers are as follows:

(1) High mechanical strength (though they are relatively light in weight)

(2) High toughness

(3) Good resilience

(4) Corrosion resistance

(5) Optical transparency

Most of the polymers are generally divided into two types: thermoplastics and thermosets. Polymers based on thermoplastics can be melted or molded. Polymers based on thermosets cannot be melted or molded [4].

\subsubsection{Polymer Based Thermoplastics}

Thermoplastics based on polymers can exist in mainly two forms: amorphous or crystalline. It is 
worth to note that the crystallinity of polymers is very low i.e. about 50\% approximately, in comparison to metals and ceramics. The amorphous polymers are less dense than crystalline polymers. Because, the crystalline polymers contain long molecular chains that are packed closely together [4]. Hence, they exhibit the following enhanced properties:
(1) Mechanical hardness
(2) Friction
(3) Stability over time period
(4) Corrosion resistance

The examples of these materials are as follows: polyethylene, low density polyethylene (LDPE), high density polyethylene (HDPE), ultra-high density polyethylene (UHDPE), etc. Among the above mentioned polymers, LDPE has occupied more than $20 \%$ of industrial plastic market. It is widely used for packaging. The amorphous polymers contain irregular molecular chains. The examples for amorphous polymers refer to polyvinyl chloride (PVA), polystyrene (PS), and polycarbonate, etc [4].

\subsubsection{Polymer based Thermosets}

These polymers can function in high temperature and pressure situations. Due to thermal stableness, thermosets are widely used as thermal insulation material. As adhesives also, they are used extensively. Examples include polyesters, aminos, and epoxide, etc. Compared to thermoplastics, thermosets are costlier and not easier for production. Also, the polymers are brittle in nature just like ceramics. But their strength can be increased by making polymer based composites. This review provides different synthesis techniques, properties and applications of both ceramics and polymers [4].

\section{Discussion and Analysis}

\subsection{Processing and Properties of Ceramics}

For electric vehicles, an anode is essentially required in lithium ion batteries. Graphite is one of the anode material used as anode for lithium ion batteries. But the specific capacity of graphite anode is limited. So various kinds of materials have been prepared for achieving the materials of high specific capacity. In one of the recent work [5], a compound of glass ceramic $\left(\mathrm{Fe}_{2} \mathrm{O}_{3}-\mathrm{TeO}_{2}-\right.$ $\mathrm{MoO}_{3}$ ) has been prepared by molten technique. Basically, $\mathrm{Fe}_{2} \mathrm{O}_{3}$ is already an established anode material with very high specific capacity i.e. $1005 \mathrm{mAh} / \mathrm{g}$. So, glass-ceramic has been made to check whether the specific capacity get enhanced or deteriorated. Oxides of tellurium, molybdenum and iron were poured in appropriate stoichiometry, in the crucibles of alumina type. Then they were heated for 30 minutes, at $850{ }^{\circ} \mathrm{C}-1000{ }^{\circ} \mathrm{C}$ with the rate of $5{ }^{\circ} \mathrm{C} / \mathrm{min}$. The obtained liquid in the molten state, was carried over to brass plate. Then another brass plate was used for the pressing. It is identified that this compound exhibit a specific capacity of $470.2 \mathrm{mAh} / \mathrm{g}$ at a current density of 1 $\mathrm{A} / \mathrm{g}[5]$.

A ceramic of composition, $\left(\mathrm{Ba}_{0.85} \mathrm{Ca}_{0.15}\right.$ $\left.{ }_{\mathrm{x}}\right)\left(\mathrm{Ce}_{\mathrm{x}} \mathrm{Zr}_{0.1} \mathrm{Ti}_{0.9}\right) \mathrm{O}_{3}$ (BCCZT), has been prepared by some group of researchers in 2018 [6]. This was an attempt made to produce the ceramic that is free of lead. Because the lead based ceramics are found to be harmful for the environment. Metal carbonates (barium carbonate and calcium carbonate) and metal oxides (zirconium dioxide, titanium dioxide and cerium dioxide) were taken in the desired stoichiometry that is mentioned above. Further, the amount of calcium has been reduced by adding cerium in various amounts such as $0.08 \%, 0.131 \%$ and $2 \%$. In this preparation method, the chemicals were dehydrated for 1 hour using oven at $220^{\circ} \mathrm{C}$. Then they chemicals were weighed, and milled for about 24 hours. Again the samples were dehydrated using oven at $90{ }^{\circ} \mathrm{C}$ for 15 hours. The dried samples were then dried in a muffle furnace at $1250{ }^{\circ} \mathrm{C}$ for 2 hours. In order to obtain fine particle sizes, the calcined samples were again milled for 24 hours. A very high pressure (i.e. 155 $\mathrm{MPa}$ ) has been applied on the samples during pressing, such that the samples of $13 \mathrm{~mm}$ diameter and $1 \mathrm{~mm}$ thickness were obtained in circular disc shapes. Then the sintering has been done at very high temperature (i.e. $1350{ }^{\circ} \mathrm{C}$ for 4 hours). XRD results shown that the peaks of diffraction spectra could arranged in such a way that the phase of tetragonal crystal symmetry can be inferred [6]. It has been observed that the grain size $(G)$ is largely reduced to $0.76 \mu \mathrm{m}$ from $7.6 \mu \mathrm{m}$, with the substitution of $2 \%$ of cerium (Ce). Very large value of piezoelectric charge coefficient $\left(\mathrm{d}_{33}\right)$ and high Curie temperature $\left(\mathrm{T}_{\mathrm{c}}\right)$ is shown by $\mathrm{BCC}_{0.00131} \mathrm{ZT}$ i.e. approximately $501 \mathrm{pC} / \mathrm{N}$ and $108.1{ }^{\circ} \mathrm{C}$ respectively [6]. Also, the remanant polarization $\left(\mathrm{P}_{\mathrm{r}}\right)$ values (shown in table 1) of 
www.rspsciencehub.com

BCZT are altered. $\mathrm{T}_{\mathrm{c}}$ is the temperature at which phase transition of most of the ceramics can be observed [7-9].

Table.1. Summary of Properties of BCZT Ceramics

\begin{tabular}{|l|l|l|l|l|c|}
\hline $\begin{array}{l}\text { S.No } \\
\cdot\end{array}$ & Composition & $\begin{array}{l}\mathbf{P r} \\
\left(\boldsymbol{\mu} \mathbf{C}_{\left.\mathbf{c m}^{2}\right)}\right)\end{array}$ & $\begin{array}{l}\mathbf{G} \\
(\boldsymbol{\mu m})\end{array}$ & $\begin{array}{l}\text { Tc } \\
\left({ }^{\circ} \mathbf{C}\right)\end{array}$ & Ref \\
\hline 1. & $\mathrm{BCC}_{0} \mathrm{ZT}$ & 7.86 & 7.6 & 105.4 & \multirow{2}{*}{6} \\
\cline { 1 - 5 } 2. & $\mathrm{BCC}_{0.00131} \mathrm{ZT}$ & 12.19 & 12.16 & 108.1 & \\
\cline { 1 - 5 } 3. & $\mathrm{BCC}_{0.02} \mathrm{ZT}$ & 3.68 & 0.76 & 72.6 & \\
\hline
\end{tabular}

One can infer that the microstructural and electrical properties of BCZT are very low, when $2 \%$ of $\mathrm{Ce}$ is substituted at calcium site. The value of dielectric permittivity (at $1 \mathrm{kHz}$ ) was observed to be around less than 5000 for BCZT. But for $\mathrm{BCC}_{0.0008} \mathrm{ZT}$ and $\mathrm{BCC}_{0.00131} \mathrm{ZT}$, the value of dielectric permittivity is between 10000 and 12000 [6].

The piezoceramics are widely used in medicine. Because they are used as ultrasonic transducers for medical imaging. Some of the suitable materials are PZT, PMN (lead magnesium niobate), lead titanate (PT), lead zirconate (PZ), PMN-PT, etc. But lead can evaporate into atmosphere when the lead based compounds are processed under high temperatures. This also may result in the direct or indirect intake of lead into the human body. Hence, headache, anemia and abdominal cramps, etc. can caused by lead [10-11]. To avoid this so, several materials have synthesized in the name of lead free ceramics, and investigated are their electrical properties. Examples include barium titanate $\left(\mathrm{BaTiO}_{3}\right)$, bismuth sodium titanate $\left(\mathrm{BiNaTiO}_{3}\right)$, potassium niobate $(\mathrm{KN})$, and Potassium sodium niobate $\left(\mathrm{KNaNbTiO}_{3}\right)$, etc [12$15]$.

As per the record, the first perovskite ferroelectric material is $\mathrm{BaTiO}_{3}$. It is well known for the use in capacitor application. It shows relatively low $\mathrm{T}_{\mathrm{c}}$ i.e. approximately $120{ }^{\circ} \mathrm{C}$. Hence, it couldn't be used at high temperatures. But several attempts were made to enhance its $\mathrm{T}_{\mathrm{c}}$. One group made a binary ceramic of composition, (1-x) $\mathrm{BaTiO}_{3}-(\mathrm{x})$ $\mathrm{BiKTiO}_{3}$, and achieved the improved $\mathrm{T}_{\mathrm{c}}$. Addition of strontium ions at barium site resulted in a dielectric permittivity of around 1350 and $d_{33}$ value of approximately $300 \mathrm{pC} / \mathrm{N}$. Another binary system, $\mathrm{BaTiZrO}_{3}-\mathrm{BaCaTiO}_{3}(\mathrm{Ti}=0.8, \mathrm{Zr}=0.2$ and $\mathrm{Ba}=0.7, \mathrm{Ca}=0.3$ ), has shown large values of
Volume 02 Issue 12S December 2020

piezoelectric and dielectric properties [16]. But still the $\mathrm{T}_{\mathrm{c}}$ value (i.e. $93{ }^{\circ} \mathrm{C}$ ) is very low for this compound, suggesting its non-applicability at high temperatures [17-18]. The properties are shown in table 2.

Table.2. Summary of Properties of Barium Titanate based Ceramics

\begin{tabular}{|l|l|l|l|l|}
\hline S.No. & Composition & $\boldsymbol{\varepsilon}_{\mathbf{r}}$ & $\begin{array}{l}\mathbf{d}_{33} \\
(\mathbf{p C} / \mathbf{N})\end{array}$ & Ref. \\
\hline 1. & $\left(\mathrm{Ba}_{0.95} \mathrm{Sr}_{0.05}\right)\left(\mathrm{Zr}_{0.05} \mathrm{Ti}_{0.95}\right) \mathrm{O}_{3}$ & 1350 & 300 & $19-20$ \\
\hline 2. & $\begin{array}{l}\mathrm{BaTi}_{0.8} \mathrm{Zr}_{0.2} \mathrm{O}_{3^{-}} \\
\mathrm{Ba}_{0.7} \mathrm{Ca}_{0.3} \mathrm{TiO}_{3}\end{array}$ & 2820 & $\sim 600$ & $17-18$ \\
\hline
\end{tabular}

$\mathrm{BiNaTiO}_{3}$, is one of the promising lead free candidate for the industrial applications. Because it exhibit very high remanant polarization that is around $38 \mu \mathrm{C} / \mathrm{cm}^{2}$. But its poling is found to be difficult because its shows high electrical conductivity as well as high coercive filed (i.e. 73 $\mathrm{kV} / \mathrm{cm}$ ). To alter its electrical properties, materials such as bismuth potassium titanate $\left(\mathrm{BiKTiO}_{3}\right)$, bismuth lithium titanate $\left(\mathrm{BiLiTiO}_{3}\right)$, etc. were used [16]. The properties of $\mathrm{BiNaTiO}_{3}$ based ceramics are summarized in table 3.

Table.3. Summary of Properties of BiNaTiO3 based Ceramics

\begin{tabular}{|c|c|c|c|c|}
\hline S.No. & Composition & $\boldsymbol{\varepsilon}_{\mathbf{r}}$ & $\begin{array}{l}\mathbf{d}_{\mathbf{3 3}} \\
\text { (pC/N) }\end{array}$ & Ref. \\
\hline 1. & $\begin{array}{c}\mathrm{BiNaTiO}_{3}- \\
0.06 \mathrm{BaTiO}_{3}\end{array}$ & 730 & 125 & 21 \\
\hline 2. & $\begin{array}{c}0.88 \mathrm{BiNaTiO}_{3} \\
-\mathrm{BiKTiO}_{3}- \\
\mathrm{BaTiO}_{3}\end{array}$ & 440 & 84 & $22-24$ \\
\hline 3. & $\begin{array}{c}0.88 \mathrm{BiNaTiO}_{3} \\
-\mathrm{BiKTiO}_{3}- \\
\mathrm{BaTiO}_{3}\end{array}$ & 1000 & 181 & 23 \\
\hline & $\begin{array}{c}0.94 \mathrm{BiNaTiO}_{3} \\
-\mathrm{BiKTiO}_{3}- \\
\mathrm{BaTiO}_{3}\end{array}$ & 490 & 92 & 23 \\
\hline
\end{tabular}

Alkali metal based perovskite materials are observed to exhibit very high $T_{c}$ values. An example include potassium sodium niobate $\left(\mathrm{KNaNbO}_{3}\right)$. It is one of the solid solution materials, just like PZT, and is formed by the compounding of the potassium niobate $(\mathrm{KNb})$ and sodium niobate $\left(\mathrm{NaNbO}_{3}\right)$. It is worth to note that $\mathrm{KNb}$ and $\mathrm{NaNbO}_{3}$ are ferroelectric and antiferroelectric respectively. $\mathrm{KNaNbO}_{3}$, possess large value of dielectric and ferroelectric 
www.rspsciencehub.com

properties. It's $T_{c}$ and $P_{r}$ values are $420{ }^{\circ} \mathrm{C}$ and 33 $\mu \mathrm{C} / \mathrm{cm}^{2}$ respectively [16]. The properties of $\mathrm{KNaNbO}_{3}$ based ceramics are summarized in table 4.

Table.4. Summary of Properties of KNaNbO3 based Ceramics

\begin{tabular}{|c|c|c|c|c|}
\hline S.No. & Composition & $\varepsilon_{\mathrm{r}}$ & $\begin{array}{l}d_{33} \\
(p C / N)\end{array}$ & Ref. \\
\hline 1. & $\begin{array}{l}\mathrm{KNaNbO}- \\
\mathrm{BiKTiO}_{3}\end{array}$ & 1260 & 251 & 25 \\
\hline 2. & KNaNbO3- $\mathrm{LiTaO}_{3}$ & $\begin{array}{l}500- \\
1260\end{array}$ & $\begin{array}{l}200- \\
230\end{array}$ & $26-27$ \\
\hline 3. & $\mathrm{KNaNbO} 3-\mathrm{LiSbO}_{3}$ & 1380 & 265 & $28-29$ \\
\hline 4. & $(\mathrm{~K}, \mathrm{Na}) \mathrm{Li}(\mathrm{Nb}, \mathrm{Ta}) \mathrm{O}_{3}$ & 1255 & 230 & 27 \\
\hline
\end{tabular}

$\mathrm{LiNbO}_{3}$, in the single crystal form, are well known for their dielectric properties. Though the magnitude of dielectric permittivity of $\mathrm{LiNbO}_{3}$ is very low (i.e. approximately 40 ), its $\mathrm{T}_{\mathrm{c}}$ value is relatively very large that is around $1150{ }^{\circ} \mathrm{C}$. Hence, these single crystals are widely used in ultrasonic transducers that are operable at very high temperatures [30-33].

\section{Conclusions}

Based on the review work that has been done, the following conclusions and recommendations have been made:

1. Chemical engineers are actively taking part in the development of ceramics and polymers, through different methods and in different ways.

2. The electrical properties of ceramiccomposites are clearly altered.

3. The grains of very fine size have been observed for $\left(\mathrm{Ba}_{0.85} \mathrm{Ca}_{0.15-\mathrm{x}}\right)\left(\mathrm{Ce}_{\mathrm{x}} \mathrm{Zr}_{0.1} \mathrm{Ti}_{0.9}\right) \mathrm{O}_{3}(\mathrm{x}$ $=0.02$ ) compound

4. The room temperature dielectric constant and $\mathrm{d}_{33}$ of $\mathrm{BaTi}_{0.8} \mathrm{Zr}_{0.2} \mathrm{O}_{3}-\mathrm{Ba}_{0.7} \mathrm{Ca}_{0.3} \mathrm{TiO}_{3}$ ceramic are very high i.e. 2820 and $\sim 600 \mathrm{pC} / \mathrm{N}$ respectively.

\section{Acknowledgement}

We thank the partial financial support of DSTSERB.

\section{References}

[1] Tiwari B, Babu T and Choudhary RNP (2020). Electrical Impedance and Modulus Characteristics of Bulk PZT Ceramics Modified by $\mathrm{Mn}$ and $\mathrm{Ce}$, International
Volume 02 Issue 12S December 2020

Research Journal on Advanced Science Hub, 2, 44-48.

[2] Anbarasu V (2011). Synthesis and Characterization of Some Rare Earth Based Ceramic Compounds, Ph.D.Thesis, Anna University.

[3] Tiwari B, Babu T and Choudhary RNP (2020). Conduction Studies of $\mathrm{Pb}\left(\mathrm{Zr}_{0.35-\mathrm{x}} \mathrm{Y}_{\mathrm{x}} \mathrm{Ti}_{0.65}\right) \mathrm{O}_{3}(\mathrm{x}$ $=0.00,0.10$ and $\mathrm{Y}=\mathrm{Mn} / \mathrm{Ce})$, International Research Journal on Advanced Science Hub, 2, 55-58.

[4] Brinson Hal F and Catherine Brinson L (2008). Polymer Engineering Science and Viscoelasticity, Springer Publishers: New York.

[5] Liu J, Li G and Wu J (2020). Fe2O3-TeO2$\mathrm{MoO} 3$ semiconductor glass-ceramics as anode materials for high specific capacity lithium ion batteries, Materials Chemistry and Physics, 258, 123894.

[6] Vijay Bijalwan, Pavel Tofel and Vladimir Holcman (2018). Grain size dependence of the microstructures and functional properties of (Ba0.85 Ca0.15- $x$ Cex) (Zr0.1 Ti0.9)O3 leadfree piezoelectric ceramics, Journal of Asian Ceramic Societies, 6:4, 384-393.

[7] Tiwari B, Babu T and Choudhary RNP (2020). Synthesis of $\mathrm{Pb}\left(\mathrm{Zr}_{0.35-\mathrm{x}} \mathrm{Mn}_{\mathrm{x}} \mathrm{Ti}_{0.65}\right) \mathrm{O}_{3}, \mathrm{x}=0.00$, $0.02,0.06,0.10$ ceramics and their structural, dielectric characteristics, Materials Research Express, 7, 055701.

[8] Tiwari B, Babu T and Choudhary RNP (2020). Dielectric, impedance and modulus spectroscopy of $\mathrm{Pb}\left(\mathrm{Zr}_{0.52-\mathrm{x}} \mathrm{Ce}_{\mathrm{x}} \mathrm{Ti}_{0.48}\right) \mathrm{O}_{3} \quad(\mathrm{x}=$ $0.00, \quad 0.10)$ ferroelectric ceramics, PhysicaScripta,95, 115806.

[9] Tiwari B, Babu T and Choudhary RNP (2020). Effect of Manganese Doping on Dielectric Characteristics of Lead ZirconateTitanate of Different Zirconium/Titanium Ratios", IOP Con. Series: Materials Science Engineering, 764, 012029.

[10]Panda PK (2009). Environmental friendly lead-free piezoelectric materials, J. Mater. Sci. 44 (19), 5049.

[11]Gordon JN, Taylor A and Bennett PN (2002). Lead poisoning: Case studies, Br. J. Clin. Pharmacol. 53 (5), 451.

[12]Safari A and Abazari M (2010). Lead-free piezoelectric ceramics and thin films, IEEE 
Trans. Ultrason. Ferroelectr. Freq. Control, 57 (10), 2165.

[13]Leontsev SO and Eitel RE (2010). Progress in engineering high strain lead-free piezoelectric ceramics, Sci. Technol. Adv. Mater. 11 (4), 044302.

[14]Takenaka T and Nagata H (2005). Current status and prospects of lead free piezoelectric ceramics, J. Eur. Ceram. Soc. 25 (12), 2693.

[15]Hosono $Y$ and Yamashita Y (2006). Piezoelectric ceramics and single crystals for ultrasonic medical transducers, J. Electroceramics 17 (2-4), 577.

[16]ElahehTaghaddos, Mehdi Hejazi and Ahmad Safari (2015). Lead-free piezoelectric materials and ultrasonic transducers for medical imaging, Journal of Advanced Dielectrics, 5, 1530002.

[17]Liu W and Ren X (2009). Large piezoelectric effect in Pb-free ceramics, Phys. Rev. Lett. 103 (25), 257602.

[18]Yan X, Lam KH, Li X, Chen R, Ren W, Ren X, Zhou Q and Shung KK (2013). Correspondence: Lead-free intravascular ultrasound transducer using BZT-50BCT ceramics, IEEE Trans. Ultrason. Ferroelectr. Freq. Control 60 (6), 1272.

[19]Xu Y and He Y (2011). Ferroelectricdielectric solid solution and composites for tunable microwave application, Ferroelectrics - Material Aspects, ed. M. Lallart (InTech, 2011), pp. 211-249.

[20]Lee STF, Lam KH, Zhang XM and Chan HLW (2011). High frequency ultrasonic transducer based on lead-free BSZT piezoceramics, Ultrasonics 51 (7), 811.

[21]Takenaka T, Maruyama K and Sakata K (1991). (Bi1/2Na1/2)TiO3- BaTiO3 system for lead-free piezoelectric ceramics, Jpn. J. Appl. Phys. 30 (9S), 2236.

[22]Hiruma Y, Nagata H and Takenaka T (2007). Phase-transition temperatures and piezoelectric properties of $(\mathrm{Bi} 1 / 2 \mathrm{Na} 1 / 2) \mathrm{TiO} 3-$ (Bi1/2Li1/2)TiO3-(Bi1/2K1/2)TiO3 lead-free ferroelectric ceramics, IEEE Trans. Ultrason. Ferroelectr. Freq. Control 54 (12), 2493.

[23]Takenaka T, Nagata H and Hiruma Y (2009). Phase transition temperatures and piezoelectric properties of (Bi1/2Na1/2)TiO3-and (Bi1/2K1/2)TiO3-based bismuth perovskite lead-free ferroelectric ceramics, IEEE Trans. Ultrason. Ferroelectr. Freq. Control 56 (8), 1595.

[24]Hejazi MM, Jadidian B and Safari A (2012). Fabrication and evaluation of a single-element Bi0.5Na0.5TiO3-based ultrasonic transducer, IEEE Trans. Ultrason. Ferroelectr. Freq. Control 59 (8), 1840.

[25]Du H, Zhou W, Luo F, Zhu D, Qu S, Li Y and Pei Z (2008).Polymorphic phase transition dependence of piezoelectric properties in (K0.5Na0.5)NbO3-(Bi0.5K0.5)TiO3 lead-free ceramics, J. Phys. Appl. Phys. 41 (11), 115413.

[26]Guo Y, Kakimoto K and Ohsato H (2005). (Na0.5K0.5)NbO3-LiTaO3 lead-free piezoelectric ceramics, Mater. Lett. 59 (2-3), 241.

[27]Saito $Y$ and Takao H (2006). High performance lead-free piezoelectric Ceramics in the $(\mathrm{K}, \mathrm{Na}) \mathrm{NbO} 3-\mathrm{LiTaO} 3$ solid solution system, Ferroelectrics 338 (1), 17.

[28]Zhang S, Xia R, Shrout TR, Zang G and Wang J (2006). Piezoelectric properties in perovskite $0.948(\mathrm{~K} 0.5 \mathrm{Na} 0.5) \mathrm{NbO}-0.052 \mathrm{LiSbO} 3$ leadfree ceramics, J. Appl. Phys. 100 (10), 104108.

[29]Zhang S, Xia R, Shrout TR, Zang G and Wang $J$ (2007). Characterization of lead free (K0.5Na0.5)NbO3-LiSbO3 piezoceramic, Solid State Commun. 141 (12), 675 (2007).

[30]MarandianHagh N, Kerman K, Jadidian B and Safari A (2009). Dielectric and piezoelectric properties of $\mathrm{Cu} 2 \mathrm{p}$-doped alkali Niobates, J. Eur. Ceram. Soc. 29 (11), 2325.

[31]Zhou Q, Lam KH, Zheng H, Qiu W and Shung KK (2014). Piezoelectric single crystal ultrasonic transducers for biomedical applications, Prog. Mater. Sci. 66, 87.

[32]Baba A, Searfass CT and Tittmann BR (2010). High temperature ultrasonic transducer up to $1000{ }^{\circ} \mathrm{C}$ using lithium niobate single crystal, Appl. Phys. Lett. 97 (23), 232901.

[33]Jiang X, Kim K, Zhang S, Johnson J and Salazar G (2013). High temperature piezoelectric sensing, Sensors 14 (1), 144. 